\title{
Organizational Culture: An Empirical Study on Selected Garment Factories in Bangladesh
}

\author{
Akhund A. Shamsul Alam \\ Senior Management Counselor, Bangladesh Institute of Management (BIM), 4, Sobhanbagh, Mirpur Road, Dhaka-1207, BANGLADESH \\ E-mail for correspondence: akhundalam@gmail.com
}

\begin{abstract}
The study is an attempt to identify and measure the perceived organizational culture in selected sample factories in the ready-made garments (RMG) sector. Based on the concept of the OCTAPACE framework - an acronym for 'Openness', 'Confrontation', 'Trust', 'Authenticity', 'Pro-action', 'Autonomy', 'Collaboration', and 'Experimentation', data were collected using OCTAPACE profile questionnaire developed by Dr. Udai Pareek. A total of 276 respondents, of which 70 are managers and 206 are workers were interviewed from 35 garment factories located in the Gazipur district of Bangladesh. Data was analyzed with Kolmogorov-Smirnov, Shapiro-Wilk and Mann-Whitney U tests as well as other suitable statistical tools. The results show that there is a significant difference in perception between managers and workers towards "Openness" and "Autonomy". The study also identifies the strong, fairly strong and weak aspects of culture in terms of values and beliefs that prevail in the selected organizations. Finally, the degree and direction of correlation between the various elements of the OCTAPACE profile are measured for developing and maintaining a better organizational culture.
\end{abstract}

Keywords: Organizational Culture, OCTAPACE Profile, Values, Beliefs JEL Classification Code: M 14

\section{INTRODUCTION}

The ready-made garment (RMG) sector is a major engine for economic growth and poverty reduction in Bangladesh. It accounts for over three-quarters of the country's export earnings, contributes to around ten percent of the GDP, and employs over 4 million workers, mostly women, in about 5,000 factories. The RMG industry has grown from 30 enterprises in 1980 to 4,000 enterprises in the 2013-14 fiscal year, with an annual growth of over $20 \%$ in the last two decades (BGMEA).

Even though the global share of Bangladesh's apparel market is growing, being the second largest RMG manufacturer after China, the industry is facing frequent labour unrests, which may have resulted from weak organizational culture.

The value of a strong organizational culture is primarily that it may act as an informal control mechanism in more complex organizations or institutions (Nohria et al., 1994). A strong organizational culture can help to control the standards of behavior in an organization that has become so large that it is impossible to control the behavior of employees by e.g. direct supervision (Stuart Haack).
Willium Ouchi (1980) also proposes that a strong organizational culture can reduce opportunistic behavior by e.g. employees, who may not feel obliged by the values and goals of the company. A strong organizational culture may therefore be seen as the binding force behind keeping organizations together, where shared values and goals may guide and control the behavior of the members of the organization (BusineessMate.Org, 2009). Furthermore, wielding a strong organizational culture can help increase employee motivation (Mihaela \& Bratianu, 2012) and revenue (Warshawsky, 2006).

This paper, therefore, attempts to identify and measure the perceived organizational culture in selected sample factories in the RMG sector.

\section{RATIONAL OF THE STUDY}

The study is very essential from the point of view of dealing and developing the organizational cultural issue. After doing a rigorous literature review, it is found that there are many studies which have been done on OCTAPACE culture in different organizations. As the ready-made garments (RMG) industry acts as the backbone of our economy and as a catalyst for the 
development of our country, the researcher inclined to conduct the research to know the organizational culture in this sector which has created a large number of employment opportunities, especially for women, in Bangladesh.

\section{ObJectives of the Study}

The study attempts to uncover the organizational culture in selected sample garment factories in Gazipur by focusing on values, and beliefs through the OCTAPACE framework. The objectives of the study are:

- To measure the perceived organizational culture and its various dimensions in selected garment factories.

- To compare the observed values and beliefs with recommended norms in selected garment factories.

- To compare the cultural profile between managers and workers in selected garment factories.

\section{HYPOTHESIS OF THE STUDY}

In light of the objectives of the study, the following null hypotheses have been proposed.

$\mathrm{H}_{1}$ : There is no significant correlation between the perceived values and beliefs outlined in OCTAPACE profile.

$\mathrm{H}_{2}$ : There is no significant difference in perception between managers and workers towards the values and beliefs outlined in OCTAPACE profile.

\section{Research Methodology}

This study, cross-sectional in nature, has been carried out in 35 garment factories located at Gazipur in Bangladesh. The survey data was collected from November 2015 to January 2016 using the 'OCTAPACE Profile Questionnaire (2015)' developed by Dr. Udai Pareek (1997). The questionnaire was personally administered to a randomly selected 276 respondents, of which 70 were managers and others were workers, at a location convenient for them. Measures of central tendency, dispersion and association (i.e., mean, standard deviation and correlation) have been used as part of descriptive statistics to analyze the data. The Kolmogorov-Smirnov test (K-S test) and Shapiro-Wilk test have been used to determine whether the data are normally distributed in order to choose the appropriate statistical test. Finally, the Mann-Whitney U Test has been used to test the hypotheses. Statistical software like the Statistical Package for Social Sciences (SPSS) has been used to analyze the data.

\section{LITERATURE REVIEW}

The term 'organizational culture' has become popular since the early 1980s. Along with the growing interest in the topic, there seems to be little agreement within the literature in respect of what 'organizational culture' actually is and, therefore, there are different definitions and perspectives on this topic. One of the most common definitions of organizational culture refers to the set of values, beliefs and behavior patterns that form the core identity of an organization (Dennison, 1984).

Edgar Schein, who is probably most closely associated with the study of organizational culture, defines it as "a pattern of basic assumptions-invented, discovered, or developed by a given group as it learns to cope with its problems of external adaptation and internal integration-that has worked well enough to be considered valid and, therefore, to be taught to new members as the correct way to perceive, think, and feel in relation to those problems (Luthans Fred, 1998)."

"In another perspective, culture may be considered as 'software' within an organization, since it is 'software', so, managers are supposed to study carefully and try to find how does each element of 'software' work on the basis of 'hardware' [simply regarding an organization as an operating hardware] (Shili Sun, 2008)."

\section{Measuring Organizational Culture (Belias AND KouSTELIOS, 2014)}

There are many ways to measure organizational culture. Harrison (1975) developed an inventory to address both the existing and the preferred culture within an organization called the Harrison's Organizational Ideology Questionnaire. The inventory consists of 15 items assessing the ideology which has been developed by an organization's employees in terms of four dimensions, orientation to power, roles, tasks and individuals.

Another famous instrument of measuring organizational culture is the Organizational Culture Inventory (OCI), developed by Cooke and Lafferty (1987). It includes 120 items which assess shared norms and expectations that are likely to affect the ways of thinking and behavior of group members, resulting 12 styles: humanistic/helpful, affiliative, approval, conventional, dependent, avoidance, oppositional, power, competitive, competence/perfectionalist, achievement, selfactualization. In 1987 as well, Glaser, Zamanou and Hacker carried out the Organizational Culture Survey, designed to address six empirical factors: teamwork and conflict, climate and morale, information flow, involvement, supervision, meetings. It includes 31 items and the responses were given on a 5-point scale.

In 1990, Hofstede, Neuijen, Ohayv and Sanders carried out a qualitative and quantitative study of 20 cases using Hofstede's Organizational Culture Questionnaire. The questionnaire included 135 items given on 5-point scales, which were based on three values: need for security, importance of work and need for authority. Within these, there are six factors relating to practice issues: process vs. outcome, employees vs. task, parochial vs. professional, open vs. closed system, loose vs. tight control, normative vs. pragmatic. 
In the mid-1990's, McKenzie's Culture Questionnaire (1995) was developed in the frame of National Health Service. It includes 76 items, and respondents tick each statement that they consider to be broadly true of their organization. The questionnaire assesses various factors: employees' commitment, attitudes to and belief about innovation, attitudes to change, style of conflict resolution, management style, confidence in leadership, openness and trust, teamwork and cooperation, action orientation, human resource orientation, organizational direction. In 1996, Walker, Symon, and Davies published the Corporate Culture Questionnaire, evaluating four principal domains: performance, human resources, decision-making and relationships. There are two versions of the Questionnaire, one of 69 and another of 126 items, each given on a 5-point Likert-type scale.

Buckingham and Coffman (2000) suggested the Core Employee Opinion Questionnaire which addressed 13 issues of business units, companies and other organizations: overall satisfaction, understanding of expectations, access to required resources, appropriate use of skills, recognition and praise for achievements, relationship with supervisors, encouragement for selfdevelopment, perceptions of worth, engagement with organizational mission, commitment of all employees, friendship appraisal, opportunities for career progression.

Cameron and Quinn (2006) created the famous Organizational Culture Assessment Instrument (OCAI), based on the four culture types. The evaluation of a culture is made through those four core values, in a $2 \times 2$ competing values, Flexibility and discretion opposing Stability and control and Internal focus and integration versus External focus and differentiation.

\section{OCTAPACE FRAMEWORK}

Organizational Culture can also be measured using OCTAPACE framework - an acronym for 'Openness', 'Confrontation', 'Trust', 'Authenticity', 'Pro-action', 'Autonomy', 'Collaboration', and 'Experimentation'. Developed by Dr. Udai Pareek (1997), this framework consists of a 40-item instrument divided into aforesaid eight dimensions given on a 4-point scale. Each cultural dimension is measured based on the response on five items per dimension. The instrument is divided into two sections. In section 1, twenty- four statements of values (three statements for each dimension) and in section 2, sixteen statements of beliefs (two statements for each dimension) have been given to measure the extent to which these values and beliefs are shared among the employees in the organization.

"A culture with OCTAPACE profile has the greater chance of achieving high involvement and satisfaction, team work, growth and a free flow of communication within the organization (Subrahmanian, 2012)." Short definitions of various dimensions of OCTAPACE culture, found in an article written by Dr. Subrahmanian (2012), are given below:

The makes an important contribution to the mental health and acculturation literature.

1. Openness: Freedom to communicate, share and interact without any fear or hesitation.

Outcome: Greater clarity of objectives and free interaction among people.

2. Confrontation: Facing the problems and challenges boldly and not shying away.

Outcome: Superior problem solving, role clarity, and willingness to deal with problems and with 'difficult' employees and customers.

3. Trust: Maintaining the confidentiality of information shared by others and company.

Outcome: Higher empathy, timely support, reduced stress and reduction and simplification of forms and procedures.

4. Authenticity: Congruence between what one feels and says.

Outcome: Sharing of feelings freely to improve interpersonal communication and reduced distortion in communication.

5. Pro-action: Taking the initiative, preplanning and taking preventive action.

Outcome: Taking and planning actions at immediate concerns.

6. Autonomy: Using and giving freedom to plan and act in one's own sphere.

Outcome: Increased self-determination, empowerment, and job satisfaction.

7. Collaboration: Giving help to and accepting help from others in a team.

Outcome: Timely work, improved communication, resource sharing.

8. Experimentation: Using and encouraging innovative approaches to solve problems.

Outcome: Development of new product, methods, and procedures.

\section{Data Analysis}

\section{Measures of Central Tendency and Dispersion}

Research objectives are addressed by examining the mean scores of the cultural values and beliefs. As said by the study, the mean scores of all the cultural values and beliefs are found to be above average. The highest score lies with 'Pro-action' (mean $=2.89$, S.D. $=0.35$ ) while the lowest score lies with 'Autonomy' (mean= 2.61, S.D. = 0.35 ). But these mean scores are not sufficiently enough to interpret organizational culture. Thus, these observed mean scores have been compared with 'low and high norms for OCTAPACE' suggested by Dr. Pareek (1997), which are presented in Table 4. 
Table 1: Comparative analysis of Mean Scores and Suggested Norms

\begin{tabular}{|l|c|c|c|c|}
\hline \multirow{2}{*}{$\begin{array}{l}\text { OCTAPACE- } \\
\text { Dimensions }\end{array}$} & \multicolumn{2}{|c|}{ Observed } & \multicolumn{2}{c|}{$\begin{array}{c}\text { Suggested Norms } \\
\text { (Jallavi \& Petonjee, 2015) }\end{array}$} \\
\cline { 2 - 5 } & $\begin{array}{l}\text { Mean } \\
\text { Score }\end{array}$ & $\begin{array}{c}\text { Std. } \\
\text { Deviation }\end{array}$ & High & Low \\
\hline Openness & 2.73 & 0.58 & 3.4 & 2.6 \\
\hline Confrontation & 2.64 & 0.37 & 3.4 & 2.6 \\
\hline Trust & 2.69 & 0.74 & 3.4 & 2.6 \\
\hline Authenticity & 2.63 & 0.72 & 2.8 & 2.0 \\
\hline Pro-action & 2.89 & 0.53 & 3.4 & 2.6 \\
\hline Autonomy & 2.61 & 0.35 & 3.2 & 2.2 \\
\hline Collaboration & 2.88 & 0.64 & 3.4 & 2.6 \\
\hline Experimentation & 2.79 & 0.73 & 3.2 & 2.2 \\
\hline
\end{tabular}

From the above table, the following inferences can be drawn:

- The mean score of 'Authenticity' is found to be very close to 'high value' of the norms table. Hence, it can be rated as strong.

- The mean scores of 'Pro-action', 'Autonomy', 'Collaboration', and 'Experimentation' are found to be between low and high value of the norms table. Thus, these values and beliefs can be rated as fairly strong.

- The mean score of 'Confrontation' is exactly the 'low value' of the norms table. Again, the mean scores of 'Trust', 'Openness' and 'Pro-action' are slightly higher than the 'low value' of the norms table. Therefore, these values and beliefs can be rated as weak.

\section{Measures of Association}

Hypothesis- 1 is addressed by examining the correlations among eight cultural values and beliefs outlined in OCTAPACE Profile. The correlation coefficients are given below in Table 2 .

Table-2: Correlations among Values and Beliefs outlined in OCTAPACE Profile

\begin{tabular}{|c|c|c|c|c|c|c|c|c|}
\hline $\begin{array}{l}\text { OCTAPACE- } \\
\text { Dimensions }\end{array}$ & $\mathrm{O}$ & C & $\mathrm{T}$ & A & $\mathrm{P}$ & $\mathrm{Au}$ & Co & $\mathrm{E}$ \\
\hline Openness (O) & 1 & & & & & & & \\
\hline Confrontation $(\mathrm{C})$ & $0.43^{* *}$ & 1 & & & & & & \\
\hline Trust $(\mathrm{T})$ & 0.08 & $0.64^{* *}$ & 1 & & & & & \\
\hline Authenticity (A) & -0.08 & $0.53^{* *}$ & $0.97^{* *}$ & 1 & & & & \\
\hline Pro-action $(\mathrm{P})$ & 0.04 & $0.23^{* *}$ & $0.55^{* *}$ & $0.52^{* *}$ & 1 & & & \\
\hline Autonomy $(\mathrm{Au})$ & 0.00 & 0.09 & $0.21^{*}$ & $0.24^{* *}$ & 0.12 & 1 & & \\
\hline Collaboration (Co) & 0.12 & -0.02 & $0.26^{* *}$ & $0.18^{*}$ & $0.79 * *$ & 0.07 & 1 & \\
\hline Experimentation (E) & $-0.24^{* *}$ & $-0.51^{* *} \mid$ & -0.11 & -0.04 & $0.58^{* *} \mid$ & 0.07 & $0.76^{* * *}$ & $* \mid$ \\
\hline
\end{tabular}

From the above correlation matrix, the following inferences can be drawn:

- There is a very strong positive correlation between 'Authenticity' and 'Trust' ( $r=0.97)$. It indicates that if there is congruence between what one feels, says and does, the trust among the employees increases in organization.

- There is a strong positive correlation between 'Proaction' and 'Collaboration' $(r=0.79)$. It shows that if employees are proactive, teamwork in the workplace increases significantly. Another strong positive correlation has been observed between 'Experimentation' and 'Collaboration' $(\mathrm{r}=0.76)$. It says that if employees work together and use one another's strength for a common cause, the culture of innovation fosters creative solutions to the most pressing problems faced by the organization. Likewise, a strong positive correlation exists between 'Confrontation' and 'Trust' $(r=0.64)$. It explains that employees trust each other if they face the problems and work together to find its solution.

- Apart from these strong relationships, there is a moderate positive correlation between 'Proaction' and 'Experimentation' $(\mathrm{r}=0.58)$. It shows that if employees anticipate issues and respond to the needs of the future, innovation and creativity increases in the organization. Another moderate positive correlation is found between 'Trust' and 'Pro-action' $(\mathrm{r}=0.55)$. It makes clear that mistrust can be reduced if employees are action oriented. A moderate positive correlation also exists between 'Confrontation' and 'Authenticity' ( $\mathrm{r}=0.53)$. It depicts that if one is true to one's own personality, spirit, or character, despite external pressures, the chances of facing the issues squarely without hiding them or avoiding them increases. Almost the same degree of correlation exists between 'Authenticity' and 'Pro-action' ( $\mathrm{r}=0.52)$. It strengthens the truth that employees who do what they say - who practice what they preach - are more likely to be seen as proactive. Similarly, a moderate positive correlation exists between 'Openness' and 'Confrontation' $(\mathrm{r}=0.43)$. It means that if employees feel free to express their ideas \& the organization is willing to take risks \& experiment with new ideas, the likelihood of facing a situation together increases even that makes them uncomfortable.

- $\quad$ Besides these strong and moderate correlations, there are statistically significant weak positive correlations among variables. At the start, correlation between 'Trust' and 'Collaboration' $(r=0.26)$ explains that employees trust each other and work together in order to solve problems and show the team spirit. Another weak positive correlation between 'Authenticity' and 'Autonomy' ( $\mathrm{r}=0.24)$ depicts that if employees are with a positive, truthful self-concept, the organization provides more autonomy. Almost the same degree of positive correlation exists between 'Confrontation' and 'Pro-action' $(\mathrm{r}=0.23)$. It indicates that if employees are pro-active, they not only surface problems but also find the solutions. The very last significant positive correlation is found between 'Authenticity' and 'Collaboration' $(\mathrm{r}=0.18)$. It explains that if employees are honest in their beliefs, speak the truth and keep their promises, the cooperation between each other increases.

- Apart from positive correlations, some negative correlations are also observed, but they are 
insignificant except for two values. One of them is found between 'Confrontation' and 'Experimentation' $(\mathrm{r}=-0.51)$. It depicts the tendency of employees to prefer working in traditional way to avoid the situation wherein conflict or interpersonal problems may arise. Another surprising negative correlation has been found between 'Openness' and 'Experimentation' $(\mathrm{r}=-0.24)$. It expresses the reality that although openness leads to innovation, too much openness at work can be counterproductive.

\section{TEST OF HyPOTHESIS}

In order to test the hypotheses, it is required to apply Student's t-Test which has an underlying assumption that the sample is drawn from normally distributed population (Bajpai, 2005). To test this assumption, the KolmogorovSmirnov test (K-S test) and Shapiro-Wilk test have been used. The test statistics are shown below in table 3 .

Table-3: Tests of Normality

\begin{tabular}{|c|c|c|c|c|c|c|}
\hline \multirow{2}{*}{$\begin{array}{l}\text { OCTAPACE- } \\
\text { Dimensions }\end{array}$} & \multicolumn{3}{|c|}{ Kolmogorov-Smirnov ${ }^{\mathrm{a}}$} & \multicolumn{3}{|c|}{ Shapiro-Wilk } \\
\hline & Statistic & $\mathrm{df}$ & Sig. & Statistic & $\mathrm{df}$ & Sig. \\
\hline Openness & .209 & 276 & .000 & .806 & 276 & .000 \\
\hline Confror & .245 & 276 & .000 & .851 & 276 & .000 \\
\hline Trust & .319 & 276 & .00 & .791 & 276 & .000 \\
\hline Authenticity & .303 & 276 & .000 & .791 & 276 & .000 \\
\hline Pro-ac & 291 & 276 & .000 & .850 & 276 & .000 \\
\hline Auton & .211 & 276 & .000 & .872 & 276 & .000 \\
\hline Collabor & .193 & 276 & .000 & .826 & 276 & .000 \\
\hline Experimentation & .198 & 276 & .000 & .848 & 276 & .000 \\
\hline
\end{tabular}

a. Lilliefors Significance Correction

The above table presents the results from two well-known tests of normality, namely the Kolmogorov-Smirnov Test and the Shapiro-Wilk Test. "The Shapiro-Wilk Test is more appropriate for small sample sizes ( $<50$ samples), but can also handle sample sizes as large as 2000 (Laerd Statistics, 2013)." In this study, since we have only 276 elements, both tests can be used. As the p-value is 0.000 in all cases, we can reject the null hypothesis (H0: sample data is normally distributed) at 5 percent level of significance. Therefore, it can be concluded that the data has not been drawn from normally distributed population. So non-parametric test- 'Mann-Whitney- $U$ ' has been applied to test whether there is a statistically significant difference in perceptions between managers and workers towards the OCTAPACE values and beliefs individually and in total. Test results have been depicted in Table 4.

Table 4: Summary of Mann-Whitney U Test

\begin{tabular}{|c|c|c|c|c|c|c|}
\hline \multirow{2}{*}{$\begin{array}{l}\text { Sr. } \\
\text { No. }\end{array}$} & \multirow{2}{*}{$\begin{array}{l}\text { OCTAPACE- } \\
\text { Dimensions }\end{array}$} & \multicolumn{2}{|c|}{ Mean Rank } & \multirow{2}{*}{$\begin{array}{c}\text { Mann- } \\
\text { Whitney } \\
\text { U }\end{array}$} & \multirow{2}{*}{$\begin{array}{c}Z \\
\text { value }\end{array}$} & \multirow{2}{*}{$\begin{array}{l}\text { p-value } \\
\text { (2-tailed) }\end{array}$} \\
\hline & & $\begin{array}{c}\text { Managers } \\
(\mathrm{n}=70)\end{array}$ & $\begin{array}{c}\text { Workers } \\
(\mathrm{n}=206)\end{array}$ & & & \\
\hline 1 & Openness & 119.41 & 144.99 & 5874.000 & -2.396 & 0.017 \\
\hline 2 & Confrontation & 126.59 & 142.55 & 6376.000 & -1.481 & 0.139 \\
\hline 3 & Trust & 140.33 & 137.88 & 7082.000 & -.238 & 0.812 \\
\hline 4 & Authenticity & 143.53 & 136.79 & 6858.000 & -.655 & 0.513 \\
\hline 5 & Pro-action & 142.50 & 137.14 & 6930.000 & -.497 & 0.619 \\
\hline 6 & Autonomy & 189.10 & 121.31 & 3668.000 & -6.263 & 0.000 \\
\hline 7 & Collaboration & 135.30 & 139.59 & 6986.000 & -.398 & 0.691 \\
\hline 8 & Experimentation & 141.99 & 137.32 & 6966.000 & -.433 & 0.665 \\
\hline & Overall & 138.09 & 139.70 & 7126.000 & -.146 & 0.884 \\
\hline
\end{tabular}

From the above table, it can be said that the differences between the individual mean ranks of managers and workers are not statistically significant at 5 percent level of significance, except the cultural values and beliefs of 'Openness' and 'Autonomy'. Therefore, the following inferences can be drawn:

- The difference in perception between managers and workers towards 'Openness' is statistically significant as the p-value is 0.017 . Hence, we can conclude that workers express their opinions more freely than managers. It might be because managers are more involved in non-standardized tasks and decision making where the probability of openness is lower than that of workers.

- The difference in perception between managers and workers towards 'Autonomy' is statistically significant as the p-value is 0.000 . Thus, we can conclude that workers are given less autonomy than managers. It is just because "each worker has a different level of need for autonomy in their job. Some workers prefer more direction from a manager and feel uncomfortable with autonomy. Additionally, if employees are not well-equippedeither in training or in personality-to exercise autonomy, it may result in workplace tension and poor performance. Finally, managers may feel that when given autonomy, workers may believe that they have authority somewhat equal to that of their direct supervisor (Marcia J. Simmering)."

- But if we consider overall culture, the study reveals that there is no statistically significant difference in perception between managers and workers towards the OCTAPACE profile all together as the p-value is 0.691 .

\section{ReCOMmENDATIONS}

Based on the findings set out above, the following recommendations are made for the selected garment factories in order to build strong organization culture:

- The management should encourage workers more to participate in decision making as it brings the sense of ownership, attachment and belongingness towards the job.

- The management should clearly pass on necessary information to all the employees so that they know what they actually are supposed to do at the workplace.

- The employees should have the liberty to share their ideas and concepts on an open forum to come to an innovative solution benefitting all.

- The superiors must be accessible to all the workers and lend a sympathetic ear in cases of queries.

- Seniors should encourage their subordinates to think about their development and take action in that direction.

- The management should conduct brain storming sessions which will generate new and innovative ideas and also collaboration among employees.

- The management should make genuine attempts to change behavior on the basis of feedback received. 
- The maximum possible autonomy should be provided to workers so that the problems are solved at their source at the grass root level.

- Employees should not only have the knowledge to describe human behavior, but also understand, predict and control the behavior.

- Employees should be more sensitive to maintain the confidentiality of information shared by others and company.

- Transparency in communication should be required at all levels for better understanding of work and better bonding among individuals.

- Employee satisfaction survey must be done at regular intervals to get the actual picture of work culture and also to find out the changing attitude among the employees.

\section{CONCLUSION}

The organizational culture in the selected garment factories is found to be fairly good overall with respect to the essential dimensions outlined in OCTAPACE profile. Some of the dimensions viz, 'Confrontation', 'Trust', 'Openness' and 'Pro-action' are being perceived as weak, which requires special attention. These values and beliefs should be cultivated among employees as these are indispensable for every organization for its effectiveness.

As stated by MSG Experts, Employees have difficulty adapting to changes in the work culture. Not all employees can be satisfied with organizational changes. Employees must spend some time to understand and adjust to a new work culture vice versa management must also give time to its employees to adapt to a new culture (MSG Experts). Employees cannot accept changes through force in a short time.

\section{REFERENCES}

Belias Dimitrios \& Koustelios Athanasios (2014), Organizational Culture and Job Satisfaction: A Review, International Review of Management and Marketing, Volume 4, No. 2, pp.132-149.

BGMEA, A Success Story of RMG Sector, Bangladesh Garment Manufacturers and Exporters Association, Available at: http://www.bgmea.com.bd/home/pages/aboutus
BusineessMate.Org (2009), Organizational Culture: An Informal Control Mechanism, Available at: http:/ / www.businessmate.org/Article.php?ArtikelId=45

Laerd Statistics (2013), Testing for Normality using SPSS Statistics, Available at: https://statistics.laerd.com/spsstutorials/testing-for-normality-using-spss-statistics.php

Luthans Fred (1998), Organizational Behaviour, International Editions, Irwin McGraw-Hill, p. 549.

Marcia J. Simmering (n.d.), Employee Autonomy (n,p.); Available at: http://www.referenceforbusiness.com/ management/A-Bud/Autonomy.html

MSG Experts (n.d.), Adjusting to Changing Organization Culture, Management Study Guide (n.d.); Available at: http:/ / www.managementstudyguide.com/adjusting-tochanging-organization-culture.htm

Nohira, Nitin \& Ghosal, Sumantra (1994), Differentiated Fit and Shared Values: Alternatives for Managing HeadquarterSbsidiary Relations, Strategic Management Journal, Volume 16, pp. 491-502.

OCTAPACE Profile Questionnaire (2015), Available at: http://docslide.us/documents/octapace-questionnaire.html

Panchamia Jallavi \& D.M. Petonjee (2015), Study of Organization Culture in Power Sector Organizations, NMIMS Management Review, Volume XXVI; Available at: http://www.nmims.edu/NMIMSmanagementreview/pdf /oct-nov/study-of-organization-culture-in-power-sectororganizations.pdf

Shili Sun (2008), Organizational Culture and Its Themes, International Journal of Business and Management, Volume 3, No. 12; Available at: http:/ / citeseerx.ist.psu.edu/viewdoc/download?doi=10.1. 1.665.4781\&rep=rep1\&type $=$ pdf

Stuart Haack (n.d.), Communicating Culture Within Organizations: A CSR Perspective, University of Southern California

Subrahmanian Mu. (2012), Achieving High Involvement \& Satisfaction through OCTAPACE Culture in IT Companies, ZENITH International Journal of Business Economics \& Management Research, Volume 2 Issue 5; Available http://www.academia.edu/5527567/OCTAPACE_SAMPLE

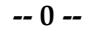

Indexed Archive Links

OCLC WorldCat: http://goo.gl/vhQzla

Google Scholar: https://goo.g1/t23FeQ

abcGATE: http://goo.gl/E6WdgA

BASE: http://goo.gl/sEd0SZ

\section{5) WorldCat Google scholar}

